\title{
Erişkin Hastada Tek Kamera Portu İle Laparoskopik Gastrostomi Post- Operatif Morbidite İlişkili Faktörler ve Sonuçların Açık Gastrostomi Tekniği İle Karşılaştırılması
}

\author{
Serhan $\operatorname{Derici}^{1} *$ \\ Dokuz Eylül Üniversitesi Tıp Fakültesi Genel Cerrahi Anabilim Dalı, İzmir, Türkiye \\ serhan.derici@deu.edu.tr \\ Orcid: 0000-0002-2828-1452 \\ *Sorumlu Yazar / Corresponding Author: Serhan Derici \\ Gönderim Tarihi / Received:30.11.2018 \\ Kabul Tarihi / Accepted:19.06.2019 \\ DOI: $10.34087 /$ cbusbed.490613
}

\begin{abstract}
Öz
Amaç: Oral yoldan beslenemeyen hastalar için enteral beslenme mideye yerleştirilen tüp vasıtasıyla yapılabilir. Bu bir Nazogastrik(NG) tüp, cerrahi(açık/laparoskopik) gastrostomi tüpü ya da peruktan endoskopik gastrostomi(PEG) tüpü olabilir. PEG uygulamasının mümkün olmadığı durumlarda cerrahi gastrostomi uygulaması gerekir. Bu makalede tek kamera portu kullanılarak U dikiş tekniği ile laparoskopik yöntemle gastrostomi tüpü yerleştirilen hastalarda post-operatif morbidite ilişkili faktörlerin tartışılması ve sonuçların açık gastrostomi sonuçlarıyla karşılaştırılması amaçlanmıştır.
\end{abstract}

Materyal ve Metot:Dokuz Eylül Üniversitesi Genel Cerrahi Anabilim Dalı'nda tek kamera portu kullanılarak Mart 2014-Mayıs 2018 tarihleri arasında laparoskopik gastrostomi ameliyatı yapılmış 30 ile Ağustos 2010-Temmuz2015 tarihleri arasında açık gastrostomi yapılmış 30 hastanın verileri geriye dönük dosya inceleme yöntemi ile elde edilerek incelendi.

Bulgular:Laparoskopik ve açık gastrostomi hastaları için grup için ortanca yaş:62(27-83) \& 59,5(19-82). İki grup için de en sık endikasyon: Baş-boyun malignitesi olan hastalarda kapalı ağız-mide pasajı. Ortalama ameliyat süresi: $37,7( \pm 15,1) \& 75,1( \pm 24,1)$ dakika. En s1k post-operatif komplikasyon Pnömoni:5(\%17)\&10(\%33) hasta, erken postoperatif mortalite: 3(\%10)\&5(\%17)hasta. Komplikasyon ilişkili risk faktörleri: Pre-op NG tüp (OR:13.189) pulmoner enfeksiyon öyküsü(OR:20.848), açık gastrostomi(OR:9,72).

Sonuç: Per-oral beslenmenin mümkün olmadığı hastalar için en güvenli beslenme şekli PEG tüpü vasıtasıyla enteral beslenmedir. PEG uygulaması yapılamayan hastalarda cerrahi gastrostomi yapılabilir. Geri dönüşsüz hastalıklarda NG aracılığıyla besleme yaparak uzun süre beklemek yerine özellikle de nozokomiyal pulmoner enfeksiyon gelişmeden gastrostomi yapılması yerinde olacaktır. Morbidite riskini daha da azaltmak için açık cerrahi yerine, oldukça minimal invaziv bir teknik olarak $5 \mathrm{~mm}$ tek kamera portu ile uygulanan U dikiş laparoskopik gastrostomi tekniği tercih edilebilir.

Anahtar Kelimeler: Perkutan Endoskopik Gastrostomi; Enteral Beslenme; Cerrahi Gastrostomi; Laparoskopik Gastrostomi; PEG.

Abstract
Objective:Patients who cannot be feed orally should be feed via the gastrostomy catheter. This catheter could be placed as surgical gastrostomy or a percutaneous endoscopic gastrostomy(PEG). Surgical gastrostomy is required when PEG is not possible. In this article, we aimed to discuss the postoperative morbidity-related factors of $U$ suture single camera port laparoscopic gastrostomy operation and compare the results with open gastrostomy procedure.

Material and method.All patients were operated in xxx xxx University Department of General Surgery between August 2010 and May 2018. The data of 30 laparoscopic gastrostomy and 30 open gastrostomy patients were analyzed retrospectively.

Results.Median age for laparoscopic and open procedure:62(27-83)\&59(19-82). The most indication in two group: obstructive head and neck malignancies. Mean operation time:37,7( $\pm 15,1) \& 75,1( \pm 24,1) \min$. The most postoperative complication: Pneumonia:7(23\%)\&10(33\%). Pneumonia-related mortality:3(10\%)\&5(17\%). The risk factors for complications: Pre-operative NG catheter feeding(OR:13.189), pre-operative medical history of pulmonary infection(OR:20.848) and open gastrostomy (OR:9,72). 
Conclusion:Parenteral nutrition for a long time increases the risk of morbidity of the patients who cannot be feed per-orally. Feeding via the PEG catheter is the best method for these patients. Patients with unsuccessful PEG attempt need surgical gastrostomy. We have to avoid the long-time NG catheter feeding. Surgical intervention should perform before nosocomial pneumonia occurred for these patients. In these patients, single-camera port laparoscopic gastrostomy technique can be preferred with low morbidity rates, instead of an open approach.

Keywords. Percutaneous endoscopic gastrostomy, Enteral feeding, Gastrostomy, Laparoscopic gastrostomy, PEG.

\section{Giris}

Oral yoldan gida alamayan hastalarda enteral beslenmenin sağlanabilmesi amacıyla gastrostomi tüpü kullanımı kabul görmüş ve sık uygulanan bir yöntemdir. Geleneksel açık gastrostomi tekniği 1894 yılında Stamm ve ekibi tarafından tarif edilmiş ve 1900 'lü yılların sonuna kadar aktif olarak uygulanmıştır [1]. Zaman içerisinde fleksible gastroskopların yaygın kullanım neticesinde, daha az invaziv bir yöntem olan peruktan endoskopik gastrostomi (PEG) işlemi 1980 yılında tanımlanmış ve erişkin hastalarda gastrostomi tüpü yerleştirme işlemi için öncelikli prosedür haline gelmiștir [2]. Sadece mide lümeni görülerek yapılan bu gastrostomi prosedürün uygulanabilmesi için oral yoldan mideye erişimin olması şarttır [3]. Perkutan endoskopik gastrostomi uygulamasının kesin kontrendikasyonu "per-oral yoldan mideye erişimin olmaması"dır.

Perkutan endoskopik gastrostomi uygulanamayan hastalar için gastrostomi tüpü cerrahi yöntemle yerleştirilir. Cerrahi gastrostomi tüpü, laparotomi yapılarak "Stamm gastrostomi" tekniği veya "laparoskopik gastrostomi" tekniği ile yerleştirilebilir. Laparoskopik gastrostomi 1990'lı yılların başlarında tanımlanmıştır. İntraabdominal giriş yapılan kamera vasıtasıyla mide duvarı dışarıdan görülerek gastrostomi tüpü yerleştirilir. Bu yöntemin değişik uygulamalarında sıklıkla 3- 4 adet trokar kullanılarak işlem gerçekleştirilir. Port sayısının azaltılmasına yönelik çalışmalar neticesinde pediatrik hastalarda sıklıkla infantlar için transabdominal $\mathrm{U}$ dikiş ile 1 adet port kullanılarak yapılan laparoskopik tüp gastrostomi ameliyatı tanımlanmıștır [4]. İnfantların karın duvarının oldukça ince olması sayesinde bu yöntem başarıyla uygulanmaktadır.

Bu makalede, infantlarda tanımlanmıș olan "tek kamera portu ve U dikiş tekniği ile yapılan laparoskopik gastrostomi” işleminin, erişkin hastalardaki uygulamasına ait sonuçların incelenmesi amaçlanmıştır. Tek kamera portlu laparoskopik gastrostomi ameliyatı için post-operatif komplikasyonlar açısından risk faktörleri tartışılmış ve sonuçlar açık "Stamm gastrostomi" ameliyatı sonuçlarıyla karşılaştırılmıştır.

\section{Materyal ve Metot}

$\mathrm{Bu}$ çalışma için öncelikle Dokuz Eylül Üniversitesi Girişimsel Olmayan Araştırmalar Etik Kurulu'ndan onay alındı (Kara no: 2018/26-03). Çalışma grubu için Mart 2014 - Mayıs 2018 tarihleri arasında tek kamera portu kullanılarak laparoskopik gastrostomi ameliyatı yapılmış olan hastalar, karşılaştırma grubu için ise Ağustos 2010- Temmuz 2015 tarihleri arasında açık
"Stamm gastrostomi" ameliyatı yapılmış hastalar çalışmaya dâhil edildi. Çalışmaya dâhil edilen hastaların verileri geriye dönük dosya inceleme yöntemi ile elde edildi. Verileri eksik olan hastalar çalışma dışında bırakıldı. Hastalara ait; yaş, cinsiyet, vücut ağırlığı, gastrostomi yapılmasina neden olan primer hastalık, yandaş hastalıklar, ameliyat öncesi beslenme şekli, ameliyat öncesi antibiyotik kullanımı ve hastane yatış süresi, endoskopik gastrostomi denemesi öyküsü, ASA skoru, ameliyat öncesi ve ameliyat sonrası kan biyokimyasal inceleme sonuçları, ameliyat sonrası beslenme ve ameliyat sonrasi komplikasyon verileri IBM SPSS Versiyon 22 programı kullanılarak kayıt altına alındı ve istatistiksel analiz yapıldı. Komplikasyon gelişimine etki eden faktörlerin belirlenebilmesi için kategorik değişkenler Pearson's Ki-kare ve Fisher's Exact test kullanılarak, sürekli değişkenler ise Student T test ve Mann Whitney U testi kullanılarak tek değişkenli analize tabi tutuldu. Bağımsız değişkenlerin komplikasyon gelişimi üzerine etkisinin incelenebilmesi için çok değişkenli analiz uygulandı ve Odds Ratio değerleri elde edildi. $\mathrm{p}<0.05$ anlamlı olarak kabul edildi.

\subsection{Ameliyat tekniği}

Hastalar genel anestezi altında supin pozisyonda ameliyata alındı. İnfraumblikal kesi yapılarak fasya askıya alınıp abdominal cerrahi girişim öyküsü olmayanlarda verres iğne ile laparotomi öyküsü olan hastalarda açık-Hasson giriş ile trokar yerleştirilerek $12 \mathrm{mmHg}$ basınçta pnömoperitoneum oluşturuldu. Girilen $5 \mathrm{~mm} 30$ derece kamera sayesinde eksplorasyon yapıldı ve sol üst kadranda gastrostomi tüpü yerleştirmek için uygun bölge belirlendi (Resim 1).

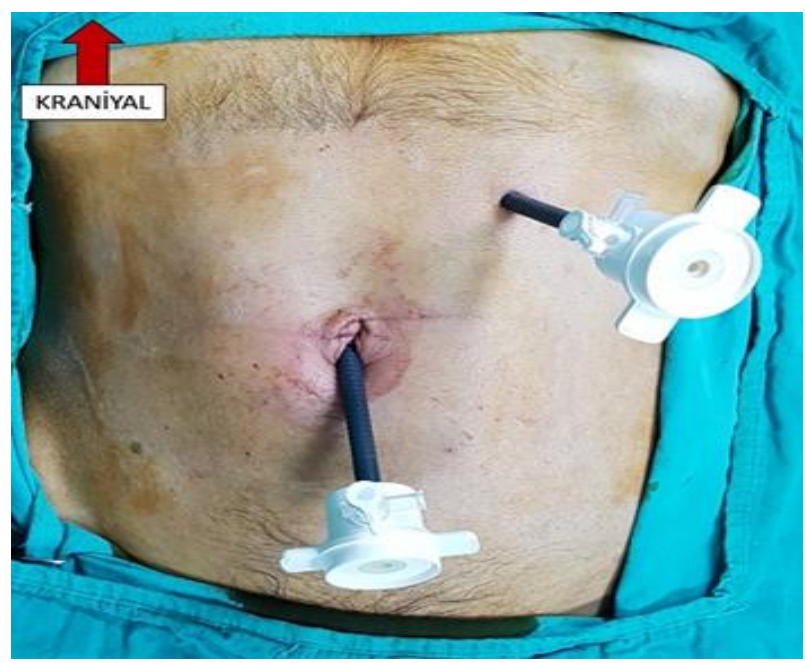

Resim 1. Trokar yerleşimleri 
Buradan 5 milimetre trokar girilerek gastrostomi tüpünün giriş yapacağ 1 yerden grasper ile mide tutularak batın duvarına doğru çekildi (bu esnada gerekli olduğu durumda $\mathrm{CO} 2$ basıncı 8mmHg'ye kadar düşürüldü). 90mm 3/8 iğneli polipropilen materyal ile cilt fasya geçilip mide duvarından seromuskuler geçiş yapılacak şekilde 3 dikiș ile mide batın duvarına asıldı (Resim 2).

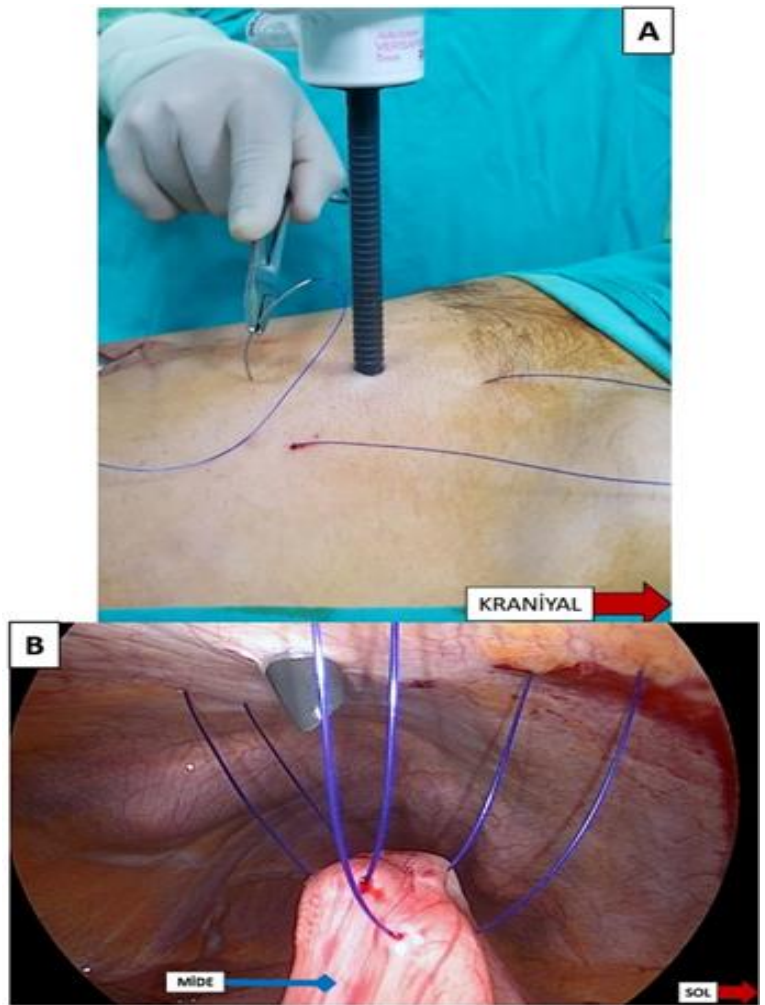

Resim 2. Trans-abdominal $U$ dikiş uygulaması A: D1ştan görünüm, B: Laparoskopik görünüm

Sol üst kadrandaki 5 milimetre trokardan girilen makas ile mide duvarı koterize edilerek açıldı ve gastrostomi tüpü girişi için delik oluşturuldu. Sol üst kadrandaki trokar çekilerek bu açıklıktan gönderilen gastrostomi tüpü mide içine yönlendirildi ve balon şişirilerek geriye kaçış engellendi (Resim 3). Dikiş materyalinin cilt travmasını engelleyen silikon tüpleri kullanılarak dikiş cilt üzerinde bağlandı ve gastrostomi tüpü kalıcı yerine çekildi (Resim 4). Gastrostomi tüpünün çalıştığından ve mideden kaçak olmadığından emin olduktan sonra desüflasyon gerçekleştirildi. İnfraumblikal fasyal defekt kapatılıp cilt suture edildi.

Açık "Stamm gastrostomi" ameliyatı için de hastalar supin pozisyonda ve genel anestezi altında ameliyat edildi. Orta hat kesi ile laparotomi yapılmasının ardından mideye iki sıra purse dikiş koyulmasını takiben midede oluşturulan açıklıktan gastrostomi tüpü yerleştirildi. İki sıra purse dikiş bağlanarak tüp giriş açıklığı invajine edilerek kapatıldı. Mide emilebilen dikiş materyali kullanılarak batın duvarına asıldı ve laparotomi açıklığı kapatıldı.

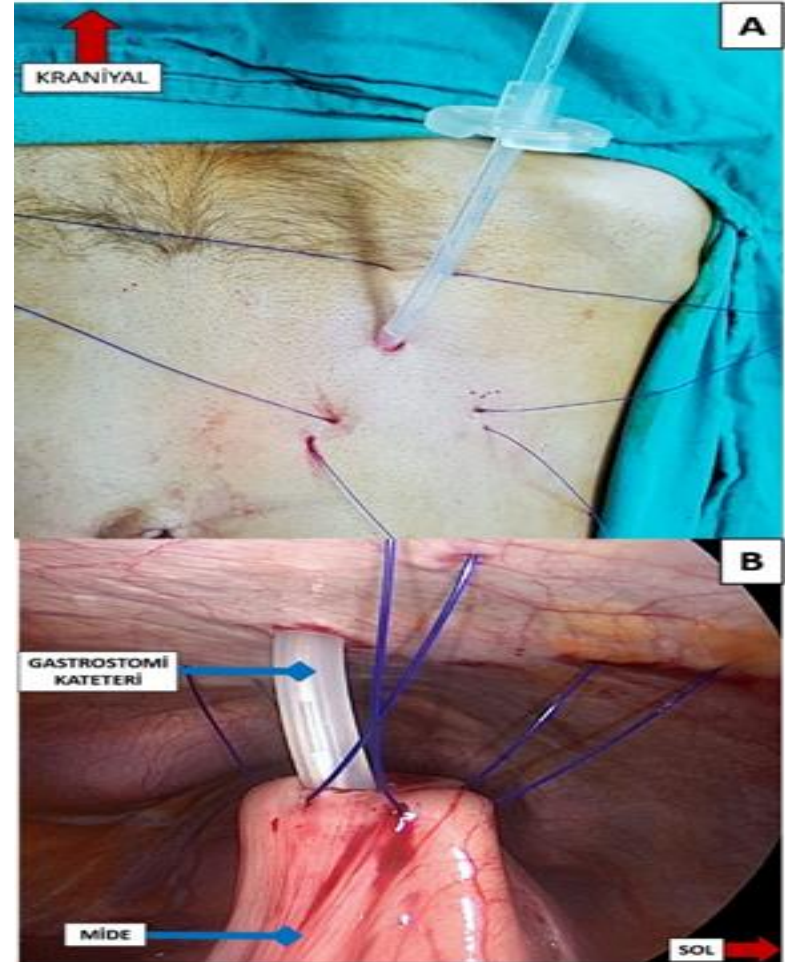

Resim 3. Gastrostomi tüpünün yerleştirilmesi A: D1ştan görünüm, B: Laparoskopik görünüm

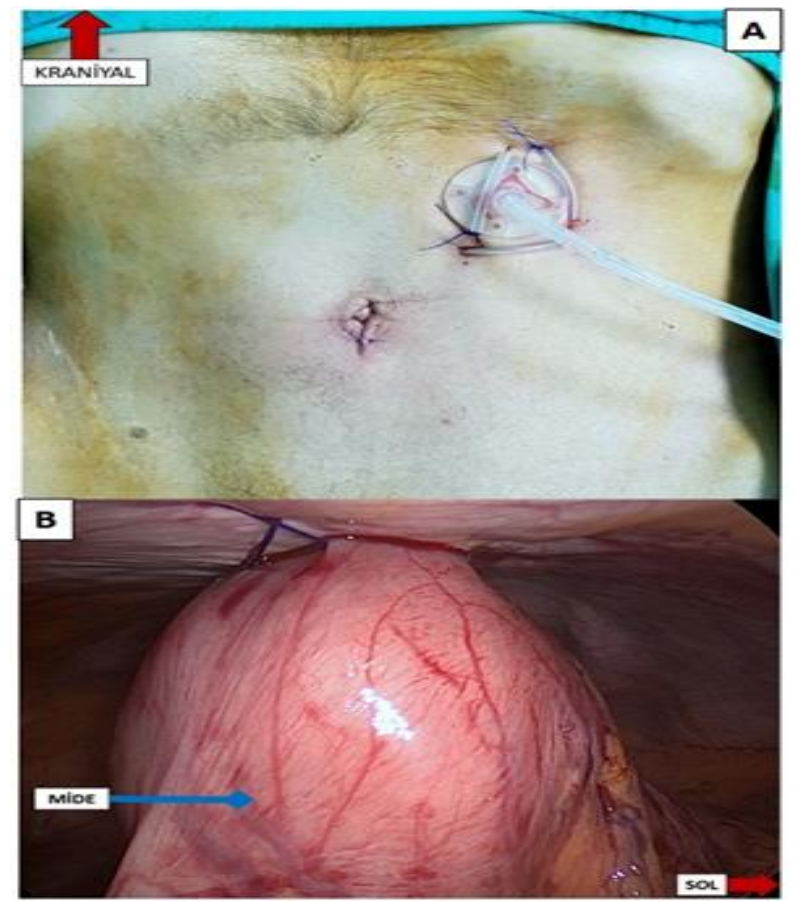

Resim 4. Cerrahi işlem sonrası görünüm A: Dıştan görünüm, B: Laparoskopik görünüm

\section{Bulgular ve Tartışma}

Her iki grupta da (Laparoskopik gastrostomi ve Açık gastrostomi) hastaların üçte ikisi erkekti. Yaş ortanca değeri laparoskopik grupta 62(27-83), açık grupta 59,50(19-82) olarak hesapland. Laparoskopik gastrostomi yapılması planlanan 30 hastanın tümünde işlemin, ek trokara ihtiyaç duymadan ve açık cerrahiye 
geçmeksizin laparoskopik olarak tamamlandığı görüldü (Tablo 1).

Tablo 1. Demografik veriler ve yandaş hastalıklar

\begin{tabular}{|c|c|c|c|}
\hline & $\begin{array}{c}\text { Laparoskopik } \\
\text { Gastrostomi }\end{array}$ & $\begin{array}{c}\text { Açık } \\
\text { Gastrostomi }\end{array}$ & $\begin{array}{c}P \\
\text { Değeri }\end{array}$ \\
\hline Yaş & $62(27-83)$ & $59,50(19-82)$ & \\
\hline Cinsiyet & & & 1 \\
\hline Kadın & $10(\% 33)$ & $10(\% 33)$ & \\
\hline Erkek & $20(\% 67)$ & $20(\% 67)$ & \\
\hline $\begin{array}{l}\text { Vücut ağırlığı } \\
(\mathrm{kg})\end{array}$ & $55(43-83)$ & $56(30-85)$ & \\
\hline $\mathrm{DM}$ & $4(\% 13)$ & $2(\% 7)$ & 0,424 \\
\hline HT & $12(\% 40)$ & $8(\% 27)$ & 0,233 \\
\hline KAH & $2(\% 7)$ & $7(\% 23)$ & 0,145 \\
\hline $\begin{array}{l}\text { Pulmoner } \\
\text { Hastalık }\end{array}$ & $16(\% 53)$ & $6 \% 20)$ & 0,007 \\
\hline KBY & $1(\% 3)$ & $1(\% 3)$ & 1 \\
\hline ASA skoru & & & 0,104 \\
\hline 1 & 0 & 0 & \\
\hline 2 & $13(\% 43)$ & $21(\% 70)$ & \\
\hline 3 & $16(\% 53)$ & $8(\% 27)$ & \\
\hline 4 & $1(\% 3)$ & $1(\% 3)$ & \\
\hline 5 & 0 & 0 & \\
\hline \multicolumn{3}{|c|}{$\begin{array}{l}\text { DM: Diabetes Mellitus, HT: Hipertansiyon, } \\
\text { KAH: Koroner arter hastalığı, KBY: Kronik } \\
\text { böbrek yetmezliği, ASA: American Society of } \\
\text { Anesthesiologist }\end{array}$} & \\
\hline
\end{tabular}

İki grup için de en sık ameliyat endikasyonu, oralgastrik pasajın çalışmasına engel olan baş-boyun malignitesiydi (Tablo 2).

Tablo 2. Gastrostomi endikasyonu

\begin{tabular}{|l|c|c|c|}
\hline & $\begin{array}{c}\text { Laparoskopik } \\
\text { Gastrostomi }\end{array}$ & $\begin{array}{c}\text { Açık } \\
\text { Gastrostomi }\end{array}$ & $\begin{array}{c}\boldsymbol{P} \\
\text { Değeri }\end{array}$ \\
\hline Endikasyon & & & 0,593 \\
\hline $\begin{array}{l}\text { Baş-boyun } \\
\text { malignitesi }\end{array}$ & $14(\% 47)$ & $18(\% 60)$ & \\
\hline ALS & $6(\% 20)$ & $2(\% 7)$ & \\
\hline $\begin{array}{l}\text { Özofagus } \\
\text { malignitesi }\end{array}$ & $6(\% 20)$ & $6(\% 20)$ & \\
\hline SVO & $2(\% 7)$ & $3(\% 10)$ & \\
\hline $\begin{array}{l}\text { Mide } \\
\text { malignitesi }\end{array}$ & $1(\% 3)$ & $1(\% 3)$ & \\
\hline $\begin{array}{l}\text { Akciğer } \\
\text { malignitesi }\end{array}$ & $1(\% 3)$ & 0 & \\
\hline $\begin{array}{l}\text { ALS: Amiyotrofik lateral skleroz } \\
\text { SVO: Serebrovasküler olay (hastalık) }\end{array}$ & \\
\hline
\end{tabular}

Ameliyat öncesi dönemde iki hasta grubunda toplam 18 hasta sadece oral yoldan ve sadece beslenme solüsyonları ile beslenmekteydi. Bu hastaların 12'si tıkayıcı maligniteleri olan ve ilerleyici pasaj açıklığ kaybı nedeniyle ameliyat planlanan hastalardı. Dört hastada ALS iki hastada ise SVO nedeniyle yutma fonksiyonlarında ilerleyici kayıp vardı. Ameliyat öncesi dönemde oral beslenme solüsyonları ile sıvı içerikli beslenmenin bile düşük miktarla ve zorlukla sağlanabildiği bu hastalarda enteral beslenmenin kalıcı temini için gastrostomi tüpü uygulaması yapıldı. İki grupta toplam 13 hasta da sadece parenteral olarak beslenebiliyordu. Geri kalan 29 hastada NG tüp, parenteral beslenme, per-oral beslenme seçeneklerinin kombinasyonlar ile uygulandığı görüldü. Gruplar arasında ameliyat öncesi beslenme yöntemleri açısından farklılık saptanmadı (Tablo 3).

Laparoskopik gastrostomi yapılan altı hastanın abdominal cerrahi girişim öyküsü vardı. Ek olarak iki hastada PEG, bir hastada cerrahi gastrostomi öyküsü, bir hastada polipropilen yama ile göbek üstü orta hat kesi fitığı onarımı öyküsü mevcuttu. Açık gastrostomi yapılan beş hasta abdominal cerrahi işlem geçirmişti. Her ne kadar eğilim abdominal cerrahi öyküsü olan hastalar için laparoskopik işlemlerin yapılmaması yönünde olsa da bu hastalarda laparoskopik gastrostomi işleminin sorunsuzca yapılabildiği görüldü. Karın boşluğuna girişte organ yaralanmasından kaçınmak için uygun manevraların kullanılmış olması ve esas ameliyatın karın içi yapışıklıkların daha az olduğu üst abdominal alanda gerçekleştirilmesinin buna katkı sağladığı düşünüldü. Uygulanan tek kamera portlu ve U dikiş tekniği sayesinde karın duvarına yapışıklığın görece daha fazla olacağı orta-alt abdominal alandan başka trokar girişine ihtiyaç duyulmadı ve abdominal cerrahi öyküsü olan hastalarda da laparoskopik gastrostomi işlemi güvenle yapılabildi [5].

İki grupta toplam $25(\% 42)$ hastada cerrahi gastrostomi işlemi öncesi daha az invaziv yöntem olarak PEG yapılmak istenmiş ancak başarılı olunamamıştı. Bu hastaların 17'sinde geçişe engel olan kitleden dolayı mideye ilerlenememiş ve PEG uygulamasında kesin kontrendikasyon olan bu engel nedeniyle işlem yapılamamıştı [3]. Sekiz hastada ise teknik başarısızlık nedeniyle PEG uygulaması tamamlanamamıştı.

İki grupta toplam $25(\% 42)$ hastada cerrahi gastrostomi işlemi öncesi daha az invaziv yöntem olarak PEG yapılmak istenmiş ancak başarılı olunamamıştı. Bu hastaların 17'sinde geçişe engel olan kitleden dolayı mideye ilerlenememiş ve PEG uygulamasında kesin kontrendikasyon olan bu engel nedeniyle işlem yapılamamıştı (3). Sekiz hastada ise teknik başarısızlık nedeniyle PEG uygulaması tamamlanamamıştı.

Laparoskopik gastrostomi grubunda hastaların ameliyat öncesinde ortanca 9(1-54) gün hastanede yattığ1 görüldü. Sekiz hasta ameliyat öncesi dönemde antibiyotik tedavisi almıştı. Ameliyatların ortalama $37,7( \pm 15,1)$ dakika sürdüğ̈̈, 8 hastada 10 milimetre kamera trokarı kullanıldı ğ 1,28 hastada $18 \mathrm{~F}$ iki hastada 20F, bir hastada $16 \mathrm{~F}$ gastrostomi tüpü yerleştirildiği saptand1. Ameliyat sonrası ortalama 2,17. günde tüpten besleme başlatılmıştı. Açık gastrostomi grubunda ise hastaların ameliyat öncesinde ortanca 7,50(1-99) gün hastanede yattığı görüldü. On iki hasta ameliyat öncesi dönemde antibiyotik tedavisi almıştı. Ameliyatların ortalama $75,1( \pm 24,1)$ dakika sürdügüu, ameliyat sonrası ortalama 3,8. günde tüpten beslemenin başlandığ saptand1. 
Tablo 3. Gastrostomi açılan hastalarda abdominal cerrahi ve PEG girişim öyküsü ve ameliyat öncesi beslenme şekli

\begin{tabular}{|c|c|c|c|}
\hline & Laparoskopik Gastrostomi & Açık Gastrostomi & $P$ Değeri \\
\hline Ameliyat Öncesi Beslenme Şekli & & & 0,184 \\
\hline Sadece Per-oral & $9(\% 30)$ & $9(\% 30)$ & \\
\hline Per-oral + Parenteral & $9(\% 30)$ & $9(\% 40)$ & $3(\% 10)$ \\
\hline Nazogastrik tüp + Parenteral & 0 & $2(\% 7)$ & \\
\hline Nazogastrik tüp aracılığıyla & $6(\% 20)$ & $7(\% 23)$ & \\
\hline Sadece Parenteral & $6(\% 20)$ & & 0.001 \\
\hline Abdominal cerrahi öyküsü & $6(\% 20)$ & $5(\% 17)$ & \\
\hline Başarısız PEG denemesi & $22(\% 73)$ & $3(\% 10)$ & \\
\hline \multicolumn{2}{|l}{} & & \\
\hline PEG: Perkutan endoskopik gastrostomi & & & \\
\hline
\end{tabular}

Ameliyat sonrası komplikasyonlar değerlendirildiğinde; laparoskopik gastrostomi grubunda beş hastada pnömoni, üç hastada ameliyat sonrası erken postoperatif mortalite (ilk 30 günlük dönemde) gerçekleştiği, bir hastada erken dönemde gastrostomi tüpünden beslenme tolerasyonu ile ilgili sorun yaşandığ1 belirlendi. Açık gastrostomi grubunda da en sık görülen komplikasyonun pnömoni (10 hasta) olduğu görüldü. $\mathrm{Bu}$ grupta beş hastada erken post-operatif mortalite geliştiği belirlendi (Tablo 4).

Tablo 4. Perioperatif Komplikasyonlar

\begin{tabular}{|l|c|c|c|}
\hline & Laparoskopik Gastrostomi & Açık Gastrostomi & $P$ Değeri \\
\hline Pnömoni & $5(\% 17)$ & $10(\% 33)$ & 0.067 \\
\hline Erken post-operatif mortalite & $3(\% 10)$ & $5(\% 17)$ & 0.706 \\
\hline Beslenmeyi tolere edememe & $1(\% 3)$ & $4(\% 13)$ & 0.353 \\
\hline İleus & 0 & $2(\% 7)$ & 0.492 \\
\hline Cerrahi alan enfeksiyonu & 0 & $7(\% 23)$ & 0.052 \\
\hline İdrar yolu enfeksiyonu & 0 & $1(\% 3)$ & 1 \\
\hline Derin ven trombozu & 0 & 0 & \\
\hline Pulmoner emboli & 0 & 0 & \\
\hline
\end{tabular}

Ameliyat sonrası ağır pulmoner komplikasyonların ve mortalitenin tartışıldığı çalışmalarda da bizim çalışmamızdaki bulgulara benzer şekilde; pre-op pulmoner hastalık öyküsünün, NG tüp varlığının ve ileri evre kanserin risk faktörleri olarak tanımlandığı görüldü [6-8].

Açık gastrostomi yapılan toplam 19 hastada postoperatif komplikasyon gelişmişken tek kamera portuyla

Tablo 5. Komplikasyon gelişimi için ameliyat tekniklerinin karşılaştırılmas

\begin{tabular}{|c|c|c|c|c|c|}
\hline & \multirow{2}{*}{$\begin{array}{l}\text { Komplikasyon } \\
\text { gelişmeyen }\end{array}$} & \multirow{2}{*}{$\begin{array}{l}\text { Komplikasyon } \\
\text { gelişen }\end{array}$} & \multirow{2}{*}{$\begin{array}{l}\text { Odds } \\
\text { Oranı }\end{array}$} & $95 \%$ Güven Aralığ 1 & \multirow[t]{2}{*}{ P Değeri } \\
\hline & & & & En düşük En yüksek & \\
\hline Açık gastrostomi* & $11(37)$ & $19(\% 63)$ & $* 5.67$ & 17.49 & 0.002 \\
\hline
\end{tabular}

Komplikasyon gelişimi açısından risk faktörleri tek değişkenli analizde incelendiğinde, laparoskopik cerrahi uygulanan hastalarda; yaşın, ameliyat süresinin, ameliyat öncesi hemoglobin, albümin, değerlerinin ameliyat sonrası hemoglobin, beyaz küre ve CRP değerlerinin komplikasyon gelişimi ile ilişkisi belirlenemedi. Tek değişkenli analiz sonuçlarına göre, ameliyat öncesi nazogastrik tüp (NG) varlığının ve ameliyat öncesi pulmoner hastalığa sahip olmanın komplikasyon ile ilişkili olduğu görüldü (Tablo 6).

Çoklu regresyon analizi yapıldığında da ameliyat öncesi pulmoner hastalığa sahip olmanın ve ameliyat öncesi nazogastrik sonda varlığının post-operatif morbidite yapılan $\mathrm{U}$ dikiş laparoskopik cerrahi uygulanan yedi hastada post-operatif komplikasyon meydana geldiği belirlendi. Ameliyat tekniklerinin post-operatif komplikasyon gelişimi ile ilişkisi incelendiğinde, tek değişkenli analizde, açık gastrostomi ameliyatı sonrası post-operatif komplikasyon gelişiminin istatistiksel anlamlı olarak daha fazla olduğu görüldü (Tablo 5). 
Tablo 6. Laparoskopik gastrostomi komplikasyon gelişimi ve değişkenler

\begin{tabular}{|c|c|c|c|c|c|}
\hline & \multicolumn{2}{|c|}{ Komplikasyon gelişmeyen } & \multicolumn{2}{|c|}{ Komplikasyon gelişen } & $P$ Değer \\
\hline Yaş & 58.2 & $( \pm 17.3)$ & 59.1 & $( \pm 10.5)$ & 0.895 \\
\hline Hastane yatışı* (gün) & 11.72 & $( \pm 12.61)$ & 18.33 & $( \pm 18.73)$ & 0.467 \\
\hline Pulmoner Enfeksiyon* & 3 & $\% 13$ & 4 & $\% 57$ & 0.033 \\
\hline $\begin{array}{ll}\begin{array}{l}\text { Antibiyotik } \\
\text { (hasta sayısı) }\end{array} & \text { kullanımı* } \\
\end{array}$ & 5 & $\% 22$ & 3 & $\% 43$ & 0.345 \\
\hline $\mathrm{NG}^{*}$ & 2 & $\% 9$ & 4 & $\% 57$ & 0.016 \\
\hline WBC* & 9.6 & $( \pm 4.7)$ & 7.3 & $( \pm 1.7)$ & 0.229 \\
\hline Nötrofil sayısı* & 7.1 & $( \pm 4.6)$ & 4.8 & $( \pm 1.5)$ & 0.176 \\
\hline Hemoglobin* & 11.5 & $( \pm 1.9)$ & 11.9 & $( \pm 2.4)$ & 0.597 \\
\hline Albümin* & 3.4 & $( \pm 0.6)$ & 3.3 & $( \pm 0.4)$ & 0.597 \\
\hline Ameliyat süresi (dakika) & 34.3 & $( \pm 13.1)$ & 49.3 & $( \pm 16.9)$ & 0.062 \\
\hline $\mathrm{WBC} * *$ & 10.9 & $( \pm 4.5)$ & 9.1 & $( \pm 4.6)$ & 0.880 \\
\hline Hemoglobin** & 11.1 & $( \pm 2.2)$ & 12.1 & $( \pm 1.6)$ & 0.367 \\
\hline CRP*** & 62.7 & $( \pm 67.2)$ & 96.7 & $( \pm 84.5)$ & 0.311 \\
\hline \multicolumn{6}{|c|}{$\begin{array}{l}\text { WBC: Beyaz Küre, CRP: C-reaktif protein, NG: Nazogastrik } \\
\text { *Pre-op } \\
\text { **Post-op }\end{array}$} \\
\hline
\end{tabular}

Tablo 7. Laparoskopik gastrostomi post-op morbidite ilişkili çok değişkenli analiz

\begin{tabular}{|c|c|c|c|c|c|c|c|}
\hline & B & S.E. & Wald & $P$ & $\frac{\text { Odds }}{\underline{\text { oran1 }}}$ & \multicolumn{2}{|c|}{$\begin{array}{c}\text { \%95 Güven } \\
\text { Araliğl }\end{array}$} \\
\hline & & & & & & Alt & Üst \\
\hline $\begin{array}{l}\text { Pre-op NG ile } \\
\text { beslenme }\end{array}$ & 3.037 & 1.345 & 5.101 & 0.024 & 20.848 & 1.494 & 290.872 \\
\hline $\begin{array}{l}\text { Pre-op Pulmoner } \\
\text { Enfeksiyon }\end{array}$ & 2.579 & 1.319 & 3.823 & 0.051 & 13.189 & 0.994 & 175.003 \\
\hline Sabit & -3.335 & 1.084 & 9.473 & 0.002 & 0.036 & & \\
\hline
\end{tabular}

Açık gastrostomi grubunda çoklu regresyon analizi yapıldığında "ameliyat öncesi hastane yatış süresi, ameliyat öncesi antibiyotik kullanım öyküsü, kan albümin düzeyi ve ameliyat öncesi pulmoner enfeksiyon" değişkenlerinin hiç biri komplikasyon gelişimine etki eden bağımsız değişkenler olarak saptanmadi.

Açık gastrostomi grubunda ameliyat öncesi NG ile beslenmenin "Laparoskopik gastrostomi" grubundan farklı olarak komplikasyon gelişimine etki etmiyor şeklinde gözükmesinde, açık gastrostomi grubunda pulmoner post-operatif komplikasyonlar kadar pulmoner sistem dişı komplikasyonların görülmüş olmasının etkili olduğu düşünüldü. $\mathrm{Bu}$ yorumun doğrulamasını yapmak amacıyla açık gastrostomi grubunda post-operatif sadece pulmoner komplikasyonlar incelendiğinde, ameliyat öncesi NG tüpü olan beş hastanın tümünde pulmoner sorun yaşandığı görüldü $(p=0,002)$. Bu grupta da ameliyat öncesi NG tüp varlığının post-operatif pulmoner komplikasyonlarla ilişkili olduğu görüldü. Bu sonuçlar özellikle NG tüp ile beslenmenin dezavantajlarının tartışıldığı makaleler ile benzerdi $[6,9,10]$.

Hastalarda beslenmenin sağlanabilmesi için hem enteral hem de parenteral yol kullanılabilir. Parenteral yolun kullanılması nutrisyonel dengenin bozulmaması için kabul edilebilir, ancak uzun süreli parenteral nutrisyon ciddi enfeksiyöz, immunolojik, endokrinolojik ve kardiyovasküler riskler taşımaktadır. $\mathrm{Bu}$ nedenle mümkün olan en kısa zamanda enteral yolla beslenme temin edilmelidir $[11,12]$.

Enteral beslenmenin olabilmesi için ağız-mide geçişinin açık, çiğneme ve yutma fonksiyonlarının aktif olması, gastrointestinal sistemde sindirime fonksiyonları ile ilgili sorununun bulunmaması gerekir. Özellikle yutma fonksiyonlarının etkilendiği kas hastalıkları, periferik / santral sinir sistemi hastalıkları ve serebrovasküler hastalık durumlarında her ne kadar pasaj açık olsa da enteral beslenme mümkün olamamaktadır. Bu durumda en s1k başvurulan yöntem nazogastrik beslenme tüpü vasıtasıyla enteral beslenmenin sağlanmasıdır. 
Tablo 8. Açık gastrostomi komplikasyon gelişimi ve değiş̧kenler

\begin{tabular}{|c|c|c|c|}
\hline & $\begin{array}{c}\text { Komplikasyon } \\
\text { gelişmeyen }\end{array}$ & $\begin{array}{c}\text { Komplikasyon } \\
\text { gelişen }\end{array}$ & $P$ Değeri \\
\hline Yaş & $54( \pm 11.02)$ & $57.74( \pm 18.99)$ & 0.557 \\
\hline Hastane yatış1* (gün) & $6.64( \pm 7.1)$ & $22.79(27.6 \pm)$ & 0.024 \\
\hline Pulmoner Enfeksiyon* & 0 & $10(\% 52.6)$ & 0.004 \\
\hline Antibiyotik kullanımı* (hasta sayısı) & 0 & $12(\% 63.2)$ & 0.001 \\
\hline $\mathrm{NG}^{*}$ & 0 & $5(\% 26.3)$ & 0.082 \\
\hline WBC* & $9.78( \pm 7.52)$ & $8.65( \pm 4.71)$ & 0.616 \\
\hline Nötrofil sayısı* & $5.89( \pm 4.02)$ & $6.56( \pm 4.54)$ & 0.685 \\
\hline Hemoglobin* & $10.86( \pm 1.71)$ & $10.65( \pm 1.39)$ & 0.723 \\
\hline Albümin* & $3.37( \pm 0.57)$ & $2.91( \pm 0.55)$ & 0.039 \\
\hline Ameliyat süresi (dakika) & $65.91( \pm 18)$ & $80.53( \pm 25.86)$ & 0.11 \\
\hline WBC** & $9.63( \pm 6.04)$ & $13.28( \pm 8.73)$ & 0.248 \\
\hline Hemoglobin** & $10.63( \pm 2.01)$ & $10.45( \pm 1.72)$ & 0.175 \\
\hline $\mathrm{CRP}^{* *} *$ & $99.73( \pm 66.09)$ & $152.10( \pm 104.82)$ & 0.183 \\
\hline \multicolumn{4}{|c|}{$\begin{array}{l}\text { WBC: Beyaz Küre, CRP: C-reaktif protein, NG: Nazogastrik } \\
\text { *Pre-op } \\
\text { **Post-op }\end{array}$} \\
\hline
\end{tabular}

Mevcut durumun geri dönüşsüz ya da ilerleyici olduğu hallerde ise PEG tüpünden besleme tercih edilmektedir. Siklıkla teknik nedenlerle PEG tüp uygulamasının yapılamadığı durumlarda cerrahi gastrostomi tüpü ihtiyacı oluşmaktadır ve bizim çalışma grubumuzda da 13 hastada ameliyat bu endikasyonla yapılmıştır.

Enteral beslenmenin sağlanamadığı bir diğer hasta grubunu tıkayıcı baş-boyun ya da özofagus-mide kanserleri olan hastalar oluşturur. $\mathrm{Bu}$ hasta grubunda NG tüp uygulaması, PEG tüp takılması lezyonların tıkayıcı vasıfta olmaları nedeniyle mümkün olamamaktadır. $\mathrm{Bu}$ durumlarda enteral beslenme, cerrahi gastrostomi tüpü vasıtasıyla yapılabilmektedir ve bizim çalışma grubumuzda da 47 hastada ameliyat bu endikasyonla yapılmıştır.Cerrahi tüp gastrostomi yöntemi ilk olarak 1894 yılında Stamm tarafından tanımlanmıştır ve enteral beslenmenin sağlanabilmesi için 100 yılı aşkın zamandır başarıyla uygulanmaktadır [1]. Minimal invaziv tekniklerin, açık cerrahi girişimlere alternatif olarak tartışıldığı son yıllarda, laparoskopik cerrahi gastrostomi yöntemleri tanımlanmış ve sıklıkla uygulanır olmuştur. Laparoskopik teknikte de açık cerrahi teknikte olduğu gibi hastalar genel anestezi altında ameliyat edilir. Konvansiyonel laparoskopik gastrostomi tekniğinde 3-4 trokar kullanılarak direk laparoskopik görüş altında mideye gastrostomi tüpü yerleştirilir. $\mathrm{Bu}$ uygulama yıllar içerisinde revize edilmiş ve daha az sayıda trokar ile yapılır hale gelmiştir. Buna örnek olarak 2010 y1lında Kandil ve ekibi 2 port kullanarak yaptıkları ve mideyi trans fasyal olarak karın dışına çektikten sonra gastrostomi tüpünü yerleştirdikleri teknikleri gösterilebilir [13]. Bu teknikte gastrostomi tüpü yerleştirmeden önce karın dışında, cilt üzerinde gastrotomi yapılması gereklidir. Erişkin hastalarda midenin $10 \mathrm{~mm}$ açıklıktan çekilmesi zordur, büyütülecek delik nedeniyle gastrostomi tüpü etrafinda oluşacak açıklık risk oluşturur.

İnfantlar için tanımlanmış tek port $U$ dikiş tekniği, erişkin hastalarda ancak 2-3 port ile ya da tüp gastrostomi kitleri kullanılarak yapılabilmektedir [4]. $\mathrm{Bu}$ tekniğin tek port ile erişkin hastada uygulanmasının önündeki temel engel, karın duvarının infantlara kıyasla ciddi derecede kalın olması ve $U$ dikişin mide duvarından geçememesidir. Bu kısıtlılığı giderebilmek için ikinci-üçüncü port devreye girmekte ve laparoskopik portegü kullanılarak $U$ dikiş mideden geçilmektedir.

Bildiğimiz kadarıyla erişkin hastada ilk kez kliniğimizde uygulanan tek port $\mathrm{U}$ dikiş laparoskopik tüp gastrostomi tekniğinde PEG yapılamayan erişkin hastalarda cerrahi gastrostomi işleminin travmasının minimalize edilmesi amaçlanmıştır ve başka ekipmana (laparoskopik gastrostomi kitleri) ihtiyaç duyulmaması sayesinde maliyet artışına yol açmadan laparoskopik gastrostomi ameliyatı yapılmıştır.

Laparoskopik tek portlu U dikiş tekniğinin etkinliği, güvenilirliği ve uygulanabilirliğinin değerlendirilmesi ve sonuçlarının gözden geçirilmesi için yapılan bu çalışmada; bu tekniğin abdominal cerrahi operasyon geçirmiş hastalarda da başarıyla uygulandığı, hiçbir 
ameliyatta ek port giriş ihtiyacı olmadığı ve açık cerrahiye geçiş yaşanmadığı görüldü. Ameliyat ve beslemeye başlama sürelerinin laparoskopik grupta açık gastrostomi grubuna kıyasla anlamlı ölçüde daha kısa olduğu, laparoskopik gastrostomi yapılan grupta anlamlı olarak daha az komplikasyon geliştiği belirlendi (Tablo 9). $\mathrm{Bu}$ sonuçlar, açık ve laparoskopik cerrahi işlemlerin karşılaştırıldığı diğer çalışmaların sonuçları ile benzerdi [14-17].

Tablo 9. Açık Gastrostomi - Laparoskopik gastrostomi

\begin{tabular}{|c|c|c|c|}
\hline & $\begin{array}{c}\text { Laparoskopik } \\
\text { Gastrostomi }\end{array}$ & Açık Gastrostomi & P Değeri \\
\hline Ameliyat süresi (dakika) & $37.7( \pm 15.1)$ & $75.1( \pm 24.1)$ & $<\mathbf{0 . 0 0 1}$ \\
\hline Gastrostomi tüpü kullanımına başlama (gün) & $2.1( \pm 1.2)$ & $3.8( \pm 1.1)$ & $<\mathbf{0 . 0 0 1}$ \\
\hline Post-operatif komplikasyon & $7(\% 23)$ & $19(\% 63)$ & $\mathbf{0 . 0 0 2}$ \\
\hline
\end{tabular}

\subsection{Kisitlılıklar}

Sonuçları paylaşılan bu çalışmanın temel kısıtlılığı prospektif bir çalışma olarak tasarlanamamış olmasıdır. Bunun yanında örneklem sayısının az oluşu bir diğer kısıtlılık olarak göze çarpmaktadır. Erişkin hastalarda bildiğimiz kadarıyla ilk defa kullanılmış olan bu tekniğin olumlu olduğunu gördüğümüz sonuçlarını hasta sayısının azlığına rağmen paylaşma amacımız, kolay uygulanabilir bu yöntemin birden çok merkez tarafindan sınanmasının arzulanmasıdır. Bu sayede daha büyük hasta gruplarında değerlendirme yapmak mümkün olacaktır.

\section{Sonuc}

Per-oral beslenmenin uygulanamadığı geri dönüșsüz ve/veya ilerleyici hastalık varlığında enteral beslenme için ilk tercih PEG tüpü olmalıdır. PEG uygulaması yapılamayan erişkin hastalar için post-operatif morbidite riskini artırmamak adına, uzun süre NG tüp kullanmadan, pulmoner hastalık gelişmeden, cerrahi gastrostomi kararı alınmalıdır. Cerrahi gastrostomi için laparoskopik yöntemlerin tercih edilmesi post-operatif komplikasyon riskini azaltacaktır. Laparoskopik yöntem olarak "tek port U dikiş gastrostomi” erişkin hastalarda da güvenle uygulanabilen bir alternatif olarak değerlendirilebilir.

\section{Teșekkür}

Dokuz Eylül Üniversitesi Tıp Fakültesi Genel Cerrahi Anabilim Dalı Öğretim üyeleri Prof.Dr. Seymen Bora ve Prof.Dr. Koray Atila'ya deneyimlerini içtenlikle paylaşmış olmaları ve bu makalenin daha iyi hale getirilmesini sağlayan kıymetli katkılarından dolayı teşekkür ederim.

\section{Referanslar}

1. STAMM, M. Gastrostomy by a new method. Med News [Internet]. 1894 [cited 2018 Sep 6];65:324-6. Available from: https://ci.nii.ac.jp/naid/10012182428/

2. Gauderer MW, Ponsky JL, Izant RJ. Gastrostomy without laparotomy: a percutaneous endoscopic technique. J Pediat Surg [Internet]. 1980 Dec [cited 2018 Nov 1];15(6):872-5. Available

from: http://www.ncbi.nlm.nih.gov/pubmed/6780678

3. Beres A, Bratu I, Laberge JM. Attention to small details: big deal for gastrostomies. Semin Pediatr Surg. 2009;

4. Georgeson KE. Laparoscopic gastrostomy and fundoplication. Pediatr Ann [Internet]. 1993 Nov [cited 2018 Oct 12];22(11):675-7. Available http://www.ncbi.nlm.nih.gov/pubmed/8290324
5. Buhmann-Kirchhoff S, Lang R, Kirchhoff C, Steitz HO, Jauch KW, Reiser M, et al. Functional cine MR imaging for the detection and mapping of intraabdominal adhesions: method and surgical correlation. Eur Radiol [Internet]. 2008 Jun 15 [cited 2019 Apr 11];18(6):1215-23. Available from: http://link.springer.com/10.1007/s00330-008-0881-5

6. Park RH, Allison MC, Lang J, Spence E, Morris AJ, Danesh BJ, et al. Randomised comparison of percutaneous endoscopic gastrostomy and nasogastric tube feeding in patients with persisting neurological dysphagia. BMJ [Internet]. 1992 May 30 [cited 2018 Nov 1];304(6839):1406-9. Available from: http://www.ncbi.nlm.nih.gov/pubmed/1628013

7. Evaristo-Méndez G, Rocha-Calderón $\mathrm{CH}$. Factores de riesgo para neumonía nosocomial en pacientes con cirugía abdominal. Cir Cir [Internet]. 2016 Jan [cited 2018 Nov 1];84(1):21-7. Available from: http://www.ncbi.nlm.nih.gov/pubmed/26259742

8. Wolkewitz M, Vonberg R, Grundmann H, Beyersmann J, Gastmeier $\mathrm{P}$, Bärwolff $\mathrm{S}$, et al. Risk factors for the development of nosocomial pneumonia and mortality on intensive care units: application of competing risks models. Crit Care [Internet]. 2008 [cited 2018 Nov 1];12(2):R44. Available

http://www.ncbi.nlm.nih.gov/pubmed/18384672

9. Baeten C, Hoefnagels J. Feeding via nasogastric tube or percutaneous endoscopic gastrostomy. A comparison. Scand J Gastroenterol Suppl [Internet]. 1992 [cited 2018 Nov 1];194:95-8. Available from: http://www.ncbi.nlm.nih.gov/pubmed/1298056

10. Mekhail TM, Adelstein DJ, Rybicki LA, Larto MA, Saxton JP, Lavertu P. Enteral nutrition during the treatment of head and neck carcinoma: is a percutaneous endoscopic gastrostomy tube preferable to a nasogastric tube? Cancer [Internet]. 2001 May 1 [cited 2018 Nov 1];91(9):1785-90. Available

from: http://www.ncbi.nlm.nih.gov/pubmed/11335904

11. Alverdy J, Chi HS, Sheldon GF. The effect of parenteral nutrition on gastrointestinal immunity. The importance of enteral stimulation. Ann Surg [Internet]. 1985 Dec [cited 2018 Nov 1];202(6):681-4. Available from: http://www.ncbi.nlm.nih.gov/pubmed/3935061

12. Deitch EA, Ma WJ, Ma L, Berg RD, Specian RD. Protein malnutrition predisposes to inflammatory-induced gut-origin septic states. Ann Surg [Internet]. 1990 May [cited 2018 Nov 1];211(5):560-7; discussion 567-8. Available from: http://www.ncbi.nlm.nih.gov/pubmed/2111125

13. Kandil E, Alabbas H, Jacob C, Friedlander P, Duchesne J, Joshi V, et al. A Simple and Safe Minimally Invasive Technique for Laparoscopic Gastrostomy. JSLS J Soc Laparoendosc Surg [Internet]. 2010;14(1):62-5. Available from:

http://www.ncbi.nlm.nih.gov/pmc/articles/PMC3021287/

14. Antoniou SA, Antoniou GA, Koch OO, Pointner R, Granderath FA. Meta-analysis of laparoscopic vs open cholecystectomy in elderly patients. World J Gastroenterol [Internet]. 2014 Dec 14 [cited 2018 Nov 22];20(46):17626-34. Available http://www ncbi.nlm nih gov/pubmed/25516678

15. Antoniou SA, Antoniou GA, Koch OO, Köhler G, Pointner R, Granderath F-A. Laparoscopic versus open obesity surgery: a 
meta-analysis of pulmonary complications. Dig Surg [Internet]. 2015 [cited 2018 Nov 22];32(2):98-107. Available from: http://www.ncbi.nlm.nih.gov/pubmed/25765889

16. Van Dusen R, Radomski M, Vaziri K, Amdur R, Knapp S, Sarani B. Comparison of complications following laparoscopic versus open gastrostomy. J Am Coll Surg [Internet]. 2013 Sep 1 [cited 2018 Nov 22];217(3):S14-5. Available from https://linkinghub.elsevier.com/retrieve/pii/S10727515130051 27

17. Biondi A, Di Stefano C, Ferrara F, Bellia A, Vacante M, Piazza L. Laparoscopic versus open appendectomy: a retrospective cohort study assessing outcomes and costeffectiveness. World J Emerg Surg [Internet]. 2016 [cited 2018 Nov 22];11(1):44. Available from: http://www.ncbi.nlm.nih.gov/pubmed/27582784

http://edergi.cbu.edu.tr/ojs/index.php/cbusbed isimli yazarın CBU-SBED başlıklı eseri

bu Creative Commons Alıntı-Gayriticari4.0 Uluslararası Lisansı ile lisanslanmıştır.

(c) (7) (8) 